\title{
Comprehensive Study on Materials used in Different Types of Additive Manufacturing and their Applications
}

\author{
Rami Alfattni \\ Department of Mechanical Engineering, \\ Umm Al-Qura University, Mecca, Makkah, Saudi Arabia. \\ Corresponding author: rafattni@uqu.edu.sa
}

(Received on June 3, 2021; Accepted on December 21, 2021)

\begin{abstract}
Additive manufacturing is center of attention now days in innovative research specially because of industrial revolutionization and commercialization. It has a number of advantages, including mass customization, design freedom, waste minimization, and rapid prototyping in breakthrough applications such as aerospace, biomedical, constructions, buildings, and even food, health, and fashion. Metals, polymers, ceramics, and composites are among the materials used, as are smart materials, biomaterials, and nanomaterials. 3D printing is gaining a lot of traction these days, and it has made huge strides in the realm of additive manufacturing. A variety of software is also being used to assist the phenomenon of $3 \mathrm{D}$ printing. The basic types of $3 \mathrm{D}$ printing, the materials utilized for $3 \mathrm{D}$ printing, and applications are discussed in this review study.
\end{abstract}

Keywords- Additive manufacturing, 3D printing, Smart materials, Biomaterials, Hybrid materials.

\section{Introduction}

Charles Hull (Wang et al., 2017) brought 3D printing, also known as Additive Manufacturing (AM), to the world in 1986 to meet the need for quick prototyping and model manufacturing. 3D printing is a collection of advanced manufacturing techniques that produce haptic $3 \mathrm{D}$ physical items from a 3D CAD model by printing line to line, point to point, or layer by layer in an additive manner (Wang et al., 2017; Chen et al., 2019). Typically, an STL (Surface Tessellation Language) file is prepared and delivered to the 3D printer (Wang et al., 2017). The toolpath for producing the layers is determined by the 3D printer, and the printer follows that toolpath until the part is finished (Mostafaei et al., 2021).

This technology is naturally nimble, allowing for quick design and manufacturing of goods that are adapted to the needs of the customer. It enables the manufacture of highly complex-shaped objects with complete design flexibility, consistent lead times, and feedstock recycling (Mostafaei et al., 2021). This method is also known as layered manufacturing, 3D fabbing, rapid prototyping, and solid freeform fabrication in the literature (Ligon et al., 2017). 3D printing is now widely employed in a variety of industries, including healthcare, agriculture, locomotive and vehicle manufacturing, and aviation (Shahrubudin et al., 2019).

Rapid prototyping has given way to soft robotics, electronic gadgets, tissue engineering, and the development of high-performance metamaterials (Kuang et al., 2019). Even though there have been considerable advancements in this field, there are still a number of issues that must be addressed in order to create AM on a big scale. These concerns include anisotropy, porosity, thermomechanical characteristics, cost, corrosion qualities, creep, and long-term stability of currently utilized materials (Ligon et al., 2017). 3D printing has the potential to transform industries and improve the production line by lowering prices, increasing production speed, tailoring capabilities, and giving 
the production line more control. Manufacturing sites can now be located close to ultimate destinations, thanks to global transportation (Shahrubudin et al., 2019). Thermoplastics, metals, ceramics, and graphene-based materials are used as construction materials to achieve this.

In the review paper by Wong et al., The advantages and disadvantages of various additive manufacturing techniques are examined. Studies are explored, as well as a step-by-step approach for learning $3 \mathrm{D}$ drawing principles from the ground up as done by $\mathrm{G}$ code which is shown in Figure 1.

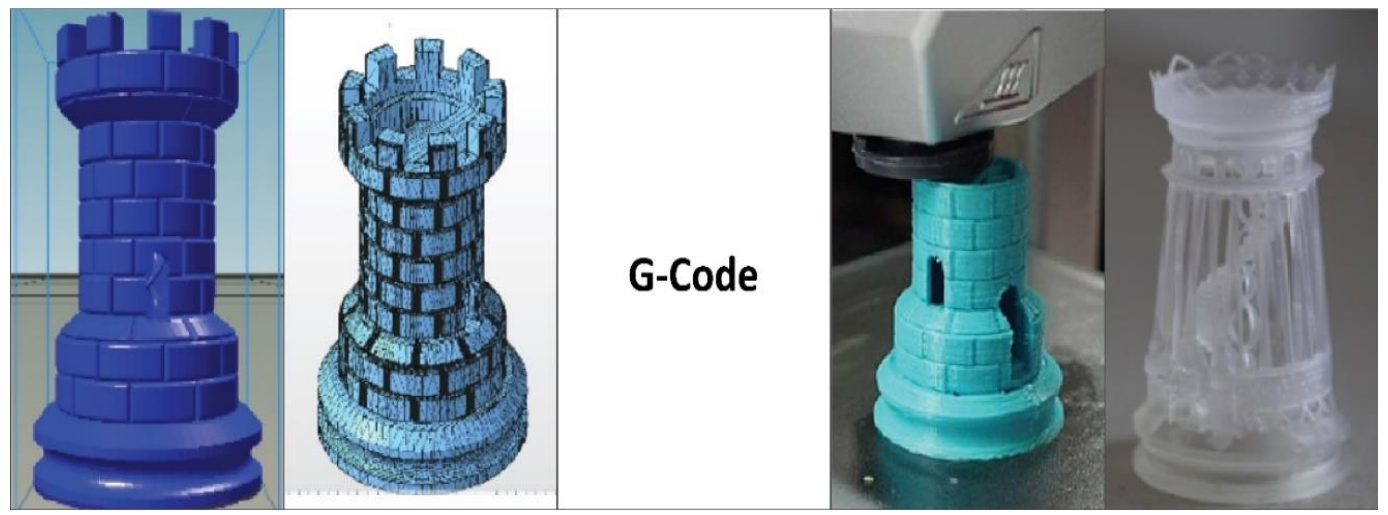

Figure 1. Steps involved in the continuous flow of 3D product fabrication by additive manufacturing technique using $\mathrm{G}$ code.

In addition, key additive manufacturing technologies are discussed, as well as their applications in the aerospace sector, medicine, autos, and architectures (Wong and Hernandez, 2012). In another review paper by Paolini et al. (2019), the increasing applications of AM in construction industry, in recent years, have been reviewed. Concrete printing, specifically concrete extrusion and powder bed methods were the focus of the majority of the study. Other materials and applications were only discussed in passing. There are huge gaps in knowledge about different types of materials and their applications (Paolini et al., 2019). Another review on additive manufacturing designs is provided, which focuses on what is already available. The goal of this article was to review additive manufacturing terminologies, trends, methods, and classification.

This article provides a comprehensive overview of designs and tools that can help with the design process. However, no information on the different materials utilized in additive manufacturing was provided (Wiberg et al., 2019). A review by Yakout et al. (2018) aimed to review various additive manufacturing processes and their applications. It also reviewed how additive parts were different from wrought parts. Azam et al. (2018) proposed an in-depth review on additive manufacturing techniques of metals. This paper gave an insight to the available metal AM techniques and compared mechanical and physical properties of the produced parts with conventional parts (Azam et al., 2018). A study by Ngo et al. (2018) gave a deep insight on methods, applications, and challenges of additive manufacturing techniques. The basic classification of materials used in AM has also been discussed thoroughly. But again, it lagged studies on the advanced materials, like smart materials, biomaterials, edible materials, used in AM along with their applications (Ngo et al., 2018). 
However, the above-mentioned studies should be improved in terms of explaining all parts of the research in the context of additive manufacturing. A variety of additive manufacturing and integrated manufacturing studies were examined. This review paper focuses on the principles of additive manufacturing, classification, and relevant approaches, as well as a complete study of material classifications used in additive manufacturing and relevant applications, all in one place. The major motivation of this review is to summarize major work which is done all around the world in additive manufacturing, this article will focus on all aspects of AM in order to provide ease for the researcher.

\section{Types of Additive Manufacturing}

3D printing is often split into two categories: fusion and non-fusion based technologies (Mostafaei et al., 2021). In 2009, the ASTM International Committee F42 on AM Technology defined many terms to distinguish between different 3D printing techniques (Ligon et al., 2017; Shahrubudin et al., 2019). These techniques were created for a variety of purposes most of them are shown in the Figure 2.

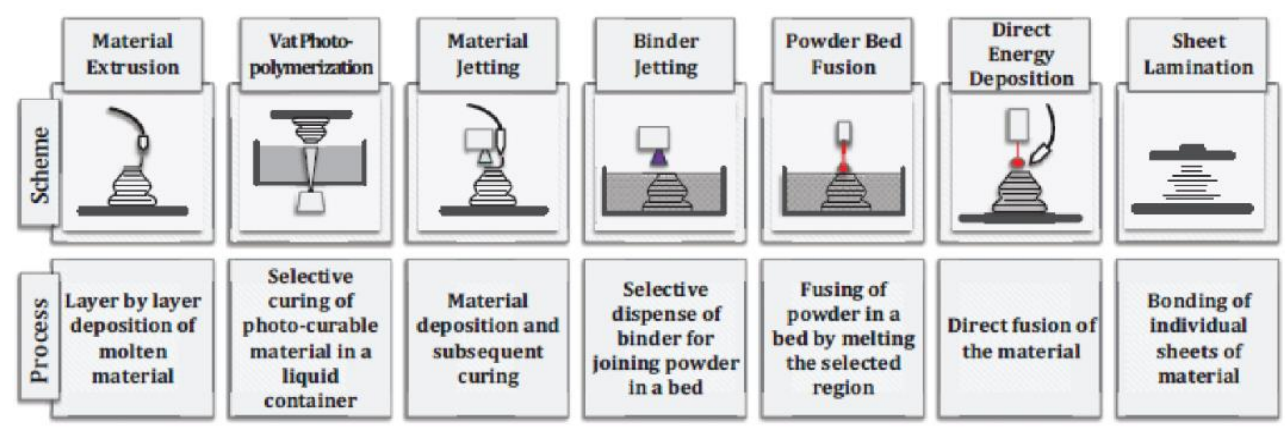

Figure 2. Categorization of additive manufacturing techniques.

\subsection{Material Extrusion}

It's about substance that's sprayed out of a nozzle. The principal material is polymer, and pieces are constructed from the bottom up, layer by layer, by heating and extruding thermoplastic. Material extrusion is divided into sub-disciplines such as fused filament fabrication (FFF), fused deposition modelling (FDM), 3D bio-plotting, and 3D dispensing. They can be utilized to create multi-material cells, as well as living and food cells.

\subsection{Material Jetting}

It is a method in which print head droplets of photosensitive materials are selectively deposited and solidify when exposed to UV light. Photopolymers, thermoplastic materials, composites, biological or hybrid materials, and ceramics are among these materials (Shahrubudin et al., 2019). This category includes inkjet printing (Ligon et al., 2017; Chen et al., 2019; Mostafaei et al., 2021).

\subsection{Binder Jetting}

This process involves the binding of a liquid agent which is carefully deposited to fuse powdered build material. It uses a jet of chemical binder to spread powder to form the layer. This process can print using metals, polymers, sands, ceramics and hybrid materials and can produce large products. (Ligon et al., 2017; Shahrubudin et al., 2019; Mostafaei et al., 2021). 


\subsection{Sheet Lamination}

A sheet of building materials is bonded together to produce an object in this method. Ultrasound additive manufacturing (UAM) and layered object manufacturing are two examples (LOM). Mostafaei et al. (2021) it is reasonably priced, extra material may be recycled, material handling is simple, and full-color prints are produced. UAM is a novel technology that employs sound waves to connect layers of metal taken from featureless foil stock (Chen et al., 2019; Shahrubudin et al., 2019), whereas LOM can produce complex geometries with the least amount of expense and time (Sanjairaj et al., 2017).

\subsection{Vat Photopolymerization}

It is an additive manufacturing technique in which liquid photopolymer is exclusively cured by light-activated polymerization in a vat. Lithographic approaches like stereo lithography, digital light processing (DLP) and multiphoton polymerization are grouped in this category (Ligon et al., 2017). The main parameters of vat polymerization are wavelength, time of exposure and the intensity of power supply. The materials used here are initially liquid and hardness when exposed to UV light (Shahrubudin et al., 2019).

\subsection{Powder Bed Fusion}

This procedure necessitates the utilization of heat energy from a laser or electron beam to fuse powder bed areas (Ligon et al., 2017). Powder bed fusion techniques include electron beam machining/melting (EBM) and selective laser sintering (SLS). SLS is a high-speed, precise, and high-surface-finish AM technique that uses a high-power laser to sinter polymer powders and yield 3D output. Metals, polymers, ceramics, hybrids, and composites are among the materials employed (Chen et al., 2019; Shahrubudin et al., 2019).

\subsection{Direct Energy Deposition}

It's a sophisticated procedure that relies on thermal energy, such as laser or plasma, to fuse materials by melting them as they're deposited. This procedure is currently exclusively used for metals and metal-based hybrids and directed energy deposition is used to regulate the grain structure of metals to a large extent. As a result, the object's quality is improved. This procedure is identical to material extrusion, with the exception that the nozzle is not fixed and can travel in any direction. This method, which can repair objects with dimensions ranging from millimeters to meters, is gaining traction in the transportation, tooling, aerospace, and oil and gas industries due to its scalability and flexibility to perform many jobs in a single system (Council, 2004).

Fusion-based technologies include direct energy deposition, laser powder bed fusion, and electron beam melting, while non-fusion methods include extrusion, material jet, binder jet, and sheet lamination (see Table 1) (Sanjairaj et al., 2017; Mostafaei et al., 2021).

Table 1. Categories of additive manufacturing techniques.

\begin{tabular}{|l|l|l|}
\hline AM Type & Techniques & Principle Group \\
\hline Material Extrusion & FDM, FFF & Material is dispensed through a nozzle or orifice \\
\hline Material Jetting & Object PolyJet, 3D Systems ProJet & Droplets of input material are deposited \\
\hline Binder Jetting & Inkjet, Zcorp, Voxeljet, ProMetal/ExOne & Liquid bonding agent is deposited to join powder \\
\hline Sheet Lamination & UAM, LOM & Material sheets are bonded \\
\hline Vat photo-polymerization & $\begin{array}{l}\text { Stereolithography (SLA), micro-SLA, } \\
\text { Digital Light Processing (DLP) }\end{array}$ & $\begin{array}{l}\text { Liquid photopolymer is cured by light-activated } \\
\text { polymerization }\end{array}$ \\
\hline Powder bed fusion & SLS, EBM & Thermal energy fuses regions of powder bed \\
\hline Direct energy deposition & Laser Engineered Net Shaping (LENS) & $\begin{array}{l}\text { Focused thermal energy is used to fuse materials by } \\
\text { melting }\end{array}$ \\
\hline
\end{tabular}




\section{Materials used for Additive Manufacturing in Production Industry}

In recent decades, the trend has been changed to produce parts of complex geometries from traditional manufacturing methods of metal forming, joining, machining, casting, and powder metallurgy to additive manufacturing. With that, many post-processing methods are eliminated. The materials used in AM ranges from high-temperature alloys, high entropy alloys, shape memory alloys, biomaterials, structural materials, thermoplastics, hybrid materials, biological tissues, hydrogels, ceramics, sand, food (Mostafaei et al., 2021).

Unlike other methods which use material subtraction, AM employs wires, powder, inks, tissues, sheets, and other feedstock to create a net shape which is either fused or added together to fabricate a final product as a tangible 3D designed product (Mostafaei et al., 2021). 3D printing needs robust and high-quality raw material to meet consistent and desired outcomes (Shahrubudin et al., 2019).

\subsection{Metals and Metallic Alloys}

Metal additive manufacturing has experienced tremendous growth. Metal AM techniques and products are used by approximately 49\% of AM firms (Ngo et al., 2018). In the aerospace sector, this technology is mostly employed for research as well as prototyping applications. Boeing, for example, has used this technique to produce the F-15 Pylon Rib (Council, 2004). The applications can also be found in the medicinal, automotive, and defense industries. In general, the AM process for metals involves melting the metallic feedstock, which might be in the form of wire or powder. Layer by layer, melted metal or alloy is converted on a bed to form a considerable portion. Powder bed fusion (PBF), direct energy deposition (DEP), and binder jetting are the most generally used processes, especially for metal printing, because they can achieve higher precision and speed (Ngo et al., 2018).

Many metallic materials are employed in powder bed fusion, including aluminum alloys, titanium alloys, stainless steel and tool steel, cobalt-based alloys, magnesium-based alloys, and nickel-based alloys (Ngo et al., 2018). The components have good mechanical qualities, and complicated forms $(0.02 \mathrm{~mm})$ are made with high precision (Murr et al., 2012). This method, however, is sluggish and only employed for small pieces. Titanium alloys are a high-performance material that is utilized in a variety of sectors. They provide complicated constructions at a cheaper cost and with less waste (Shahrubudin et al., 2019). Nowadays, Ti and Ti6Al4V are widely employed in aerospace and biomedical applications (Ngo et al., 2018).

Steels used in AM include maraging steels, austenitic steels, stainless steels, tool steels, and precipitation hardened steels. These are often used in applications requiring extreme strength and hardness, including as tools and molding dies. Murr et al. (2012) reported on the manufacture of 17-4 PH stainless steel using selective laser melting and discovered that the outcomes can be altered depending on the SLM atmosphere. In an argon atmosphere, he tested martensitic and austenitic powders and discovered that both were transformed to martensite, however in a nitrogen atmosphere, pre-austenitic powder remained in the austenite phase, as did martensitic powder.

Because aluminum alloys are easy to work with and inexpensive, there is little financial incentive to use them in additive manufacturing. Because the molten condition of aluminum does not allow for a large melting pool, it is usually produced using the PBF process (Ngo et al., 2018). The great thermal conductivity of aluminum, on the other hand, reduces thermal stresses and enables for speedier AM operations. AlSi12. Vora et al. developed an anchorless selective laser melting process that decreased residual stresses. He also highlighted those residual stresses in SLM can 
cause property reductions, but that with ASLM these can be readily ignored and tested on an aluminum-silicon alloy. The most often used aluminum alloys in AM are (Vora et al., 2015) and AlSi10Mg (Mertens et al., 2020). Figure 3 shows that the aluminum silicon alloy left side was produced using SLM technology and was supported in an overhanging position, whereas the rightside spring was produced using ASLM without any support and was easily compressed without any plastic deformation, indicating that the ASLM produced spring had no residual stresses. The same thing happened with martensitic powder, which stayed in the austenite phase.
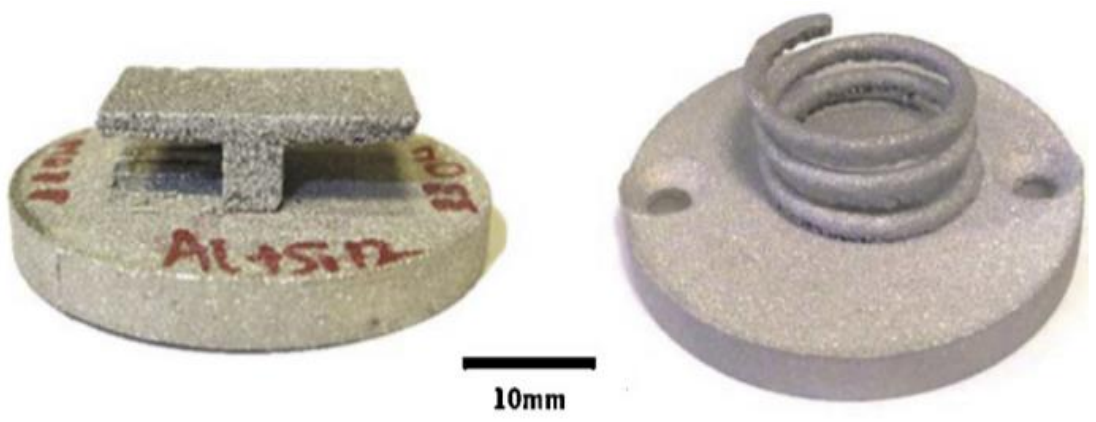

Figure 3. Aluminum silicon alloy produced from SLM on left and ASLM on right.

Nickel-based superalloys Inconel 625 and Inconel 718 AM are nickel-based superalloys used in high-temperature applications (Ngo et al., 2018). $\mathrm{CoCr}$ alloys are used in a wide range of applications, including biomedical and dental applications. Demir and Previtali. used SLM technology to fabricate $\mathrm{CoCr}$ stents and discovered that it can readily replace different shaping processes for stent manufacture (Demir and Previtali, 2017). Magnesium alloys are employed in resorbable biological applications. 316L stainless steel is the most preferred choice for biomaterials when paired with 3D printing for unique and customized parts for use in prostatectomy. 316L stainless steel is the most common choice when paired with 3D printing for unique and bespoke parts for use in prostheses and implants (Sing et al., 2020). Ti6Al4V has been employed in a range of biomedical applications, including orthopedic implants, due to its high strength-to-weight ratio, biocompatibility, corrosion resistance, and lowered elastic modulus, which is closer to that of bone (Sing et al., 2020). AM is used to make dental prosthesis out of CoCrMo alloys (Sing et al., 2020). Finally, chemical desegregation can be used to print MMC-based components, a procedure that has been widely used in bulk metallic glass research to make two-phase metal matrix composites by adding Be and $\mathrm{Cu}$ to $\mathrm{Zr}$-Ti-Nb alloys (Hofmann et al., 2014a).

The utilization of high strength alloys, magnetic alloys, high entropy alloys, functionally graded materials, and bulk metallic glasses in AM applications has been the topic of recent research in the field of metallic materials and alloys. These alloys outperform ordinary alloys in terms of fracture resistance, corrosion and oxidation resistance, tensile strength, and strength-to-weight ratio. Some of the developed alloys used in AM are CoCrCuFeNiAl, CoCrCuFeNiAlTi, CoCrFeNi, ZrTiVCrFeNi, and TiZrNbMoV (Ngo et al., 2018).

Metallic magnetic particles are employed in AM production techniques in addition to aerospace, healthcare, and information technology applications. Among the iron-based alloys used are Ni-Fe$\mathrm{V}, \mathrm{Ni}-\mathrm{Fe}-\mathrm{Mo}, \mathrm{Fe}-30 \% \mathrm{Ni}$, and $\mathrm{Fe}-\mathrm{Si}-\mathrm{B}-\mathrm{Cu}-\mathrm{Bn}$. Metallic eyewear is also made via 3D printing. (Ngo et al., 2018). 


\subsubsection{Metallic Material Properties for AM}

The majority of metals and alloys used today cannot tolerate AM processes as the melting and solidification dynamics would create microstructure defects like columnar grains and periodic cracks, Zhang et.al in his research showed that laser has a threshold value of 340j/mm3 above which high density materials can easily be melted and sintered without any imperfections and cracks. He tested $\mathrm{Al}-\mathrm{Cu}-\mathrm{Mg}$ sample and found extraordinary supersaturated dendritic structure with UTS of $402 \mathrm{MPa}$ and Yield strength of 276Mpa (Zhang et al., 2016) as shown in Figure 4.

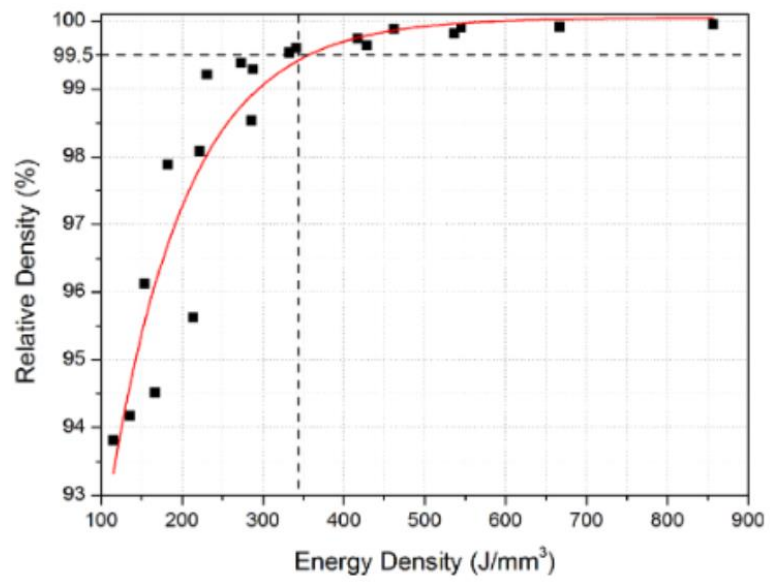

Figure 4. Relative density of $\mathrm{Al}-\mathrm{Cu}-\mathrm{Mg}$ sample with respect to laser energy.

Controlling the microstructure and porosity is critical. The primary defect that can cause fracture propagation is porosity, which can be managed by adjusting the applied volume energy as well as the initial material feedstock. Low energy results in irregularly shaped voids in the material (Vilaro et al., 2011), whereas high energy results in spherical pores (Vilaro et al., 2011; Wycisk et al., 2014). Homogeneity and flowability are improved by these round pores. Contaminants must also be kept under control. The microstructure produced by AM manufacturing is finer than that produced by traditional processes, which is also determined by the construction direction. In the order of printing, the anisotropy of the metal material with higher strength and strain is desired. Surface roughness and material flaws must be considered for fracture mechanical behavior and fatigue strength of the product, since increased surface roughness can cause stress concentration and lead to early failure (Wycisk et al., 2014). Inadequate bonding between metallic layers can further limit the material's fatigue resistance in AM parts (Körner et al., 2014). According to a study by Martin et al., solidification difficulties can be managed by utilizing nanoparticles that nucleate throughout the additive manufacturing process to prevent alloy solidification. They created this approach with $\mathrm{Al}$ alloys that weren't originally generated by $\mathrm{AM}$, such as $\mathrm{Al} 6061$ and $\mathrm{Al} 7075$ (Martin et al., 2017). In order to create metallic products using Am, phase diagrams of multicomponents of the materials must be utilized to analyses the sorts of phases that will arise at the interface between two alloys, which can aid in the assessment of undesirable phase control (Hofmann et al., 2014a; Hofmann et al., 2014b).

\subsection{Polymeric Materials}

Because of their physical, chemical, mechanical, and structural excellences, advancements in polymer matrix composites have resulted in their utilization in scientific and engineering 
applications (Singh et al., 2020). Table 2 shows data from Dizon et al. (2017) on several polymers generated by additive manufacturing, as well as their tensile strength density and tensile modulus. The tensile strength of RGD525 at high temperatures is the highest, whereas polypropylene is the lowest. The polymers have lightweight, cheap cost, ductility, long life, and processing ease qualities (Dizon et al., 2017), and their applications include aerospace, toy manufacturing, biomedical, and architectural domains. Thermoplastic filaments, resin, powder, and reactive monomers are all used as polymers in AM techniques (Ngo et al., 2018).

FDM is mostly used in the commercial 3D printing of polymeric materials. A spool of thermoplastic filaments with varying diameters, such as acrylonitrile butadiene styrene (ABS), polypropylene (PP), polyethylene (PE), and polylactic acid (PLA), is melted and then extruded through the nozzle, and the product is built on a platform that solidifies instantly in the FDM technique (Dizon et al., 2017; Shahrubudin et al., 2019).

PLA has poor mechanical characteristics but is ecologically benign, whereas ABS has excellent mechanical properties but emits a foul odour (Kuo et al., 2016). When compared to conventional injection molding, however, 3D printing has demonstrated improved mechanical qualities such as orthotropic behavior with robust asymmetry and elastic-plastic capabilities in both compression and tension (Song et al., 2017). In the FDM filament method for 3D printing, Nylon 6 is utilized as an alternative to ABS matrix (Boparai et al., 2016). Fiber reinforcement in the polymeric matrix improves mechanical qualities and represents a possible 3D printing breakthrough (Ferreira et al., 2017). Thermoplastics with a high melting point, such as PEEK and PMMA, are also employed in AM (Lee et al., 2017). Table 3 shows different techniques of AM along with the input material, advantages, and disadvantages for polymers.

Table 2. Overview of some polymer mechanical properties produced by AM.

\begin{tabular}{|c|c|c|c|c|}
\hline Process & Material & Density $\left(\mathbf{g} / \mathbf{c m}^{\mathbf{3}}\right)$ & Tensile strength (MPa) & Tensile Modulus (GPa) \\
\hline SLA & Polypropylene-like visijet flex & 1.19 & 38 & 1.6 \\
\hline SLA & ABS-like, Visijet impact & 1.18 & 48 & 2.6 \\
\hline SLA & Polycarbonate-like, visijet clear & 1.17 & 52 & 2.6 \\
\hline SLA & High temp, Visijet High temp & 1.23 & 66 & 1.4 \\
\hline SLS & General purpose nylon & 0.93 & 48 & 1.6 \\
\hline SLS & Biocompatible Nylon & 0.93 & 44 & 3.2 \\
\hline Polyjet & High temp RGD525 & 1.18 & 70 & \\
\hline
\end{tabular}

To preserve quality, the polymeric filament must be able to bear forces both before and after melting. Polymeric feed is also used in stereolithography, which prints photocurable resins like acrylic or epoxy under UV light of a specified wavelength, a process known as photopolymerization (Lee et al., 2017). In photopolymerization-based additive manufacturing, reactive oligomers and comonomers are ideal. As photo-based monomers, UV curable acrylates and epoxies are commonly used. Also used are vinyl-ether monomers (Stansbury and Idacavage, 2016). Other materials used in additive manufacturing to improve part density, mechanical characteristics, and defect minimization include pressure in the printing build chamber (Stansbury and Idacavage, 2016). For the SLS technique, powdered polyamide PA12 and Nylon 12, polyacrylonitrile butadiene styrene, polystyrene, polycarbonate (PC), polystyrene, high-density polyethylene polyether ether ketone (PEEK), and others are employed (Stansbury and Idacavage, 2016). Green composites are also now available. These are products derived from the natural world. Wood flour, wood fibres, and naturalorganic fillers are the most often used natural fillers because they are easy to produce from sawmill 
wastes and have excellent thermo-mechanical qualities (Singh et al., 2020). Biopolymers such as polyethylene glycol diacrylate (PEGDA), polylactic acid (PLA), and polycaprolactone (PCL) are used for scaffolding in 3D biomedical applications. PEGDA inherits photosensitivity and has a great ability to keep 3D shape after being hydrated (Do et al., 2015), however cell adhesion is a difficulty due to innate hydrophobicity. As a result, nanocrystalline hydroxyapatite (Do et al., 2015) is used as a filler (Manapat et al., 2017). Ferrous oxide and ferric oxide nanoparticles were combined with photopolymers to create ferrromagnetic responsive polymeric composites (Do et al., 2015).

Table 3. Different techniques of AM along with the input material, advantages, and disadvantages for polymers.

\begin{tabular}{|c|c|c|c|c|}
\hline Technique & State of Starting Material & Polymer Material & Advantages & Disadvantages \\
\hline FDM & Filament & PC, ABS, PLA any nylon & $\begin{array}{l}\text { Cost-effective, good } \\
\text { strength and multi- } \\
\text { material capability }\end{array}$ & $\begin{array}{l}\text { Anisotropy, nozzle } \\
\text { clogging }\end{array}$ \\
\hline SLA & Liquid Photopolymer & $\begin{array}{l}\text { Photocurable resin like epoxy } \\
\text { or acrylate-based resins }\end{array}$ & High printing resolution & $\begin{array}{l}\text { Cytotoxicity, material } \\
\text { limitation }\end{array}$ \\
\hline SLS & Powder & PCL and polyamide powder & $\begin{array}{l}\text { High strength and easy } \\
\text { removal of support } \\
\text { powder }\end{array}$ & $\begin{array}{l}\text { High cost, powdery } \\
\text { surface, }\end{array}$ \\
\hline Powder Bed & Powder & $\begin{array}{l}\text { Any material used as a powder } \\
\text { with a binder }\end{array}$ & $\begin{array}{l}\text { Low cost, ease of } \\
\text { removal of support } \\
\text { powder, multi-material } \\
\text { capability }\end{array}$ & $\begin{array}{l}\text { Clogging of binder } \\
\text { jet, } \\
\text { contamination }\end{array}$ \\
\hline 3D plotting & Liquid or Paste & PCL, PLA, hydrogel & $\begin{array}{l}\text { High printing resolution, } \\
\text { soft material capability }\end{array}$ & $\begin{array}{l}\text { Low mechanical } \\
\text { strength, slow process }\end{array}$ \\
\hline
\end{tabular}

Due to their permanently crosslinked network of chains, thermoset polymers are typically nonrecyclable. As demonstrated in Figure 5, 3D printing has developed a polymer recycling strategy, reducing polymer waste. The development of a novel thermoset and high-temperature vitrimer epoxy ink (Berretta et al., 2017).

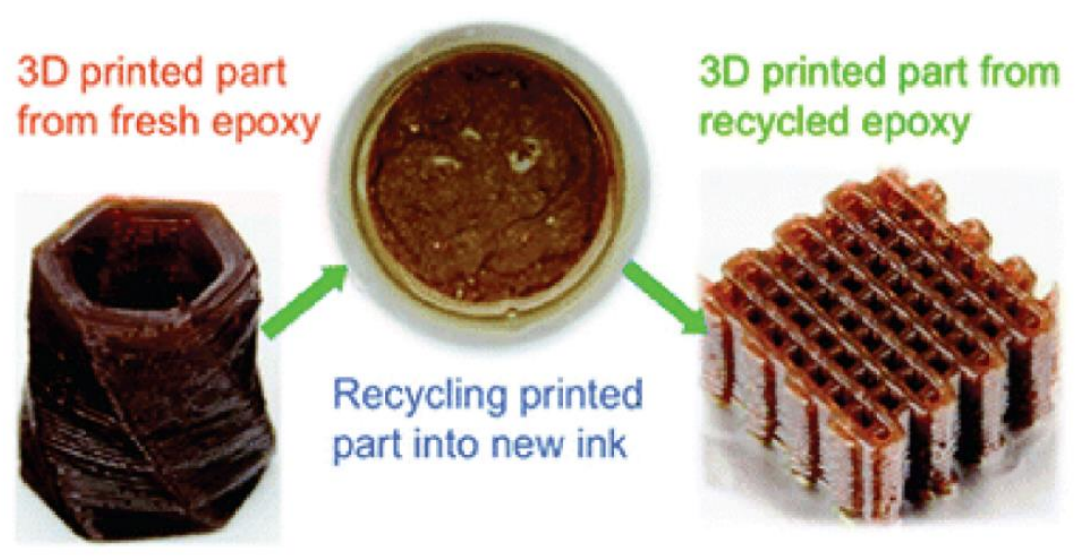

Figure 5. High temperature and recycled 3D thermoset polymeric products.

High temperature polymers are currently developed using FDM process. A study by Berretta et al. indicated that PEEK reinforced with carbon nanotubes were developed (Berretta et al., 2017). Other 
examples of high mechanical, high thermal and chemical resistance are polyethyleneimine (PEI), PEEK, poly ether ketone ketone (PEKK) and PS (Berretta et al., 2017; Arif et al., 2020). Another study by Kishore et al. developed PEKK loaded with carbon fibres, which is another high temperature polymeric composite, and studies its thermal behaviour and viscosity performance (Kishore et al., 2016). Medical PEEK-PEEK OPTIMA thermal composite was developed by Valentan et al. (2013).

Majority of the studies on high temperature polymers rely on trial and error method and are explaining mechanical performances of fabricated parts with very little detail on the methods used to define the parameters for the process (Arif et al., 2020). The enhanced electric conductive and high temperature polymers are used in applications like sensors and actuators in electronic devices, radio frequency interference (RFI) and Electromagnetic Interference (EMI) in cellular phones and computer, floor heating elements and human implants (Mohiuddin and Hoa, 2011). Moreover, carbon nanotubes play very important role in the enhancement of the electric conductivity of these 3D printed polymers when these are mixed with polymers like PEEK. Therefore, they are greatly admirable for newer areas like electrostatic charge dissipation, pressure sensors, vehicle weight sensors in highways, electronic equipment, gas sensors (Mohiuddin and Van Hoa, 2011).

\subsubsection{Fibre Reinforcement in the Polymeric Matrix for 3D Printing}

The incorporation of various types of reinforcement has resulted in mechanical qualities that are promising. Reinforcements, particularly particles, are relatively straightforward to infuse with polymer matrix in liquid form in SLA, powder form in SLS, and filament form in FDM (Wang et al., 2017). The inclusion of carbon fibres to the ABS resin feedstock was emphasised in a study by Tekinalp et al. (2014), who investigated the load-bearing potential of the resulting composite part. Love et al. produced carbon fibres in ABS polymer and discovered that if the loading conditions for the fibres are different, the coefficient of thermal expansion and thermal conductivity will change, as shown in Table 4. The finished 3D printed parts showed increased strength and rigidity, as well as less deformation (Love et al., 2014).

Table 4. Coefficient of thermal expansion and thermal conductivity of ABS polymer.

\begin{tabular}{|c|c|c|}
\hline Material & Coefficient of thermal expansion (micrometer/m $\mathbf{m}^{\mathbf{C}}$ ) & Conductivity (W/m K) \\
\hline ABS & $87.32 \pm 6.17$ & 0.177 \\
\hline ABS/CF 13\% parallel to deposition & $9.85 \pm 0.84$ & 0.397 \\
\hline ABS/CF 13\% perpendicular to deposition & 106.3 & 0.156 \\
\hline
\end{tabular}

Alumina particles have also been added to polymeric matrices to create a wear-resistant material that will be used as a filament in FDM (Singh et al., 2016). In addition, nanofillers are used (Han et al., 2017). These nano-fillers are used to improve the polymeric composite's physical, mechanical, thermal, and non-flammability qualities (Bhattacharya, 2016). Nanomaterials are also being employed in 3D printing, either directly or indirectly via mixing with the host matrix. These nanoparticles can enhance chemical and electrical characteristics while also lowering the sintering temperature (Nguyen et al., 2016). Postiglione et al. developed a low-cost LDM approach for fabricating conductive 3D microstructures from PLA matrix including nanoparticles and multiwalled carbon nanotubes (Postiglione et al., 2015). Nanoparticles have a problem with aggregation and significant light scattering in nanocomposites due to their high nano-filler content (Han et al., 2018). Another nanofiller, a vapour-grown carbon filler, which is essentially a single-walled carbon nanotube, is employed in ABS matrix polymers to improve mechanical properties, resulting in 
minimal porosity and uniform distribution of fibres (Ngo et al., 2018). Quantum dots (QD) were employed in a photopolymer resin in another investigation. QDs can absorb UV light, and the rheology of the matrix material was changed, resulting in a product with unique optical features (Elliott et al., 2012). Glass beads, which improve the product's tensile and storage modulus (Chung and Das, 2006), copper or iron particles (Nikzad et al., 2011), aluminium or aluminium oxide to improve wear resistance (Boparai et al., 2015), and ceramics reinforcements are also added in polymeric composites to improve dielectric permittivity (Dinaharan et al., 2016). By Shemelya et al. (2015) in addition, carbon black, carbon nanotubes, carbon fibre, metallic powders, and graphite are often utilised as reinforcements in high temperature and high conductivity polymers with elastomeric rubbers such as SBR, EPDM, and NBR as the matrix (Mohiuddin and Van Hoa, 2011).

To this day, new materials are being studied in order to develop 3D printing of polymer composites. This combination of additive manufacturing with polymer matrix composites has a lot of industrial promise in terms of mechanical and functional properties. However, in terms of quick prototyping and mass customisation of industrial working parts, polymer matrix composites are still far behind traditional technologies in terms of speed and reproducibility (Ngo et al., 2018).

\subsection{Ceramic Materials}

Dealing with ceramics in AM technology is one of the most significant challenges when compared to polymers and metals. The ceramic powder cannot be fused together by applying high temperature up to their melting point or glass transition temperature (Wang et al., 2017; Panda et al., 2019). Deckers et al. studied various techniques of AM using ceramic input material, and today ceramic parts are made without cracks or porosity by optimization of processing parameters. The evaluation is performed in the process in terms of incorporating colloidal processing technique or perform extra densification step (Zocca et al., 2015). Parallel processing of multiple ceramic components, low cost of raw material, manufacturing scalability makes powder-based AM technology as one of the most economical AM methods. Still, one limitation is the availability of starting material for the ceramic feedstock (Zocca et al., 2015). Eckel et al. (2016) developed a novel approach to formulate ceramic 3D printed parts which involved the use of pre-ceramic monomers mixed with UV photo-initiator.

Moreover, ceramic parts are also formed by selective deposition of the liquid binder onto ceramic particles, i.e. binder jetting process or particular fusion of ceramic powder bed with a laser. However, all these processes are limited by slow fabrication rates (Eckel et al., 2016). The most common methods of making ceramic products are inkjet printing, powder bed fusion, stereolithography and paste extrusion. These methods may or may not need post-treatment methods and results in dense products (Ngo et al., 2018).

Curved, porous and complex shapes like honeycomb, micro-lattices, corkscrew are fabricated via stereolithography. These parts showed excellent thermal stability when pyrolyzed at thousanddegree centigrade. The ceramic parts made from 3D printing are used for thermal protection systems, electronic device packaging, propulsion components, microelectromechanical system and porous burners (Eckel et al., 2016). In Figure 6, it has been clearly shown that the high temperature and recycled 3D thermoset polymeric products are usually created by the same approach. The advanced ceramics have also been used in tissue engineering and biomaterials as scaffolds for bones and teeth (Ngo et al., 2018). A porous ceramic material made from alumina with an addition of CuSO4 has been developed by Liu et al. (2011) which has very high flexural strength (Maurath and Willenbacher, 2017). Selective laser gelation (SLG) is a process that combines both sol-gel 
and SLS technique for ceramic matrix composites (Liu et al., 2011).

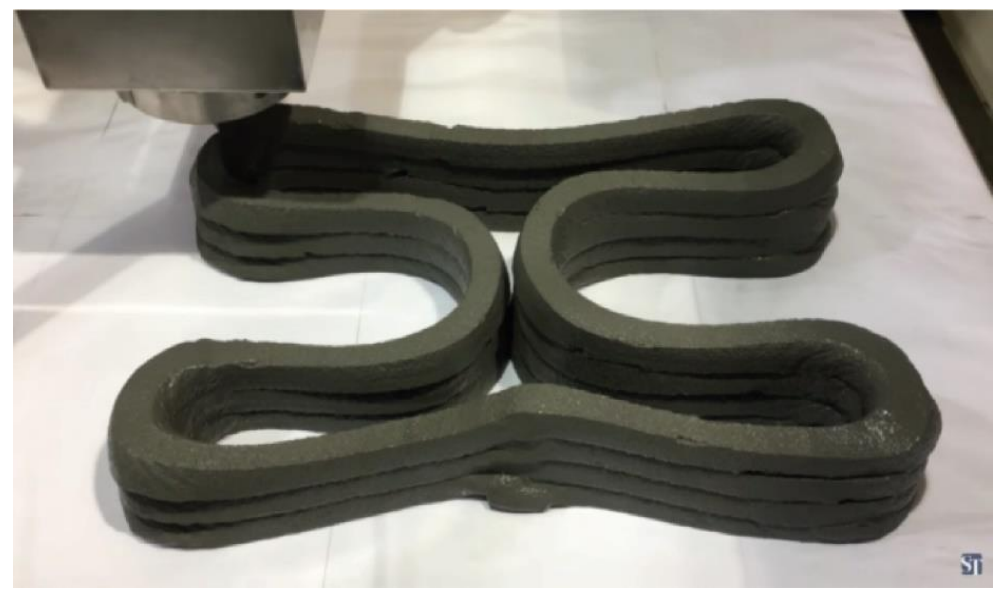

Figure 6. High temperature and recycled 3D thermoset polymeric products.

The type of ceramic powders which do not melt at a lower temperature of laser heating or easily fuse, a lower melting temperature binder is used which holds the ceramic structure in shape, and the green powder after removing excess powder is then sintered (Liu et al., 2011).

The primary method of post-curing of ceramic products results from phase changing as in crystallization of liquid phase by freeze-drying or freezing (Dehurtevent et al., 2017). One study by Vorndran et al. used a similar technique with phosphoric acid as the binder for the manufacturing of $\beta$-tricalcium phosphate ceramics. It resulted in high mechanical properties, faster setting and high printing resolution (Vorndran et al., 2008). Some ceramifiable monomers are derived from polymers like silicon oxycarbide, which can be 3D printed and then polymerized by UV and sintered at a higher temperature to create high-quality intricate ceramic lattice (Eckel et al., 2016). Ceramics such as tricalcium phosphates, calcium sulphate, porcelain, hydroxyapatite, alumina, ceramic composites, bioactive glasses and zirconia products are also manufactured using 3D printing technique (Shahrubudin et al., 2019).

\subsubsection{Ceramics Mode of Calcium Phosphate}

Calcium phosphate is a biomaterial with a chemical structure similar to teeth and bone and consist of calcium and phosphate ions. The difference in properties depends on the $\mathrm{Ca}$ and $\mathrm{P}$ ratios $(\mathrm{Ngo}$ et al., 2018). Tricalcium phosphate (TCP) is a derivative of CaP compound with phases like $\alpha$ and $\alpha$ 'phases that form at high temperature and $\beta$ phase which forms at a lower temperature (Ngo et al., 2018). Various studies have been concluded around TCP. For instance, Vorndran et al. fabricated porous $\beta$-TCP scaffolds by applying binder jetting technique on 5 wt $\%$ hydroxypropyl methylcellulose modified $\beta$-TCP.

Santos et al. (2012) also reported working with $\beta$-TCP and resulted in dense, porous, stable phased, high mechanical properties bearing biocompatible binder jetted scaffold he found that as temperature is increased from $1250^{\circ} \mathrm{C}$ to $1400^{\circ} \mathrm{C}$ then its mechanical properties were enhanced with respect to it compressive strength increased dramatically while porosity was reduced. This means high temperature sintering is better for ceramic materials (Santos et al., 2012). 
Hydroxyapatite (HAP) is another ceramic-based biomaterial derived from TCP with a ratio of $\mathrm{Ca}$ and $\mathrm{P}$ as 1.67 as similar to that of bone structure. It has better compatibility than other CaP's compounds. Seitz et al. produced binder jetted HAP scaffold designed with microchannels sized $450 \mu \mathrm{m}$ with a wall thickness of $330 \mu \mathrm{m}$ as desired in bone structure (Seitz et al., 2005). Another calcium phosphate-based compounds are tetra-calcium phosphate and dicalcium phosphate, which are widely being used for bone scaffolds (Ngo et al., 2018).

\subsubsection{Calcium Sulphate}

Calcium sulphate is an inorganic biomaterial compound used in tissue engineering. But it possesses low mechanical performance owing to its brittle nature. The use of an organic compound in the binder and initial powder can enhance toxicity levels (Ngo et al., 2018). However, heat treatment is performed on the final 3D printed product and composition, microstructure and mechanical behaviour were greatly influenced. This was done by Asadi et al. who studied an optimization of binder jetting of calcium sulphate and mechanical strength of the final 3D printed porous part. He observed that printing in the x-direction with a layer thickness of $89 \mu \mathrm{m}$ and a delay time of $300 \mathrm{~ms}$ could result in high-quality scaffold prototypes in terms of compressive strength, dimensional accuracy, porosity and Young's Modulus (Asadi-Eydivand et al., 2016).

\subsubsection{Alumina}

Alumina is a ceramic that remains electrically and mechanically stable at high temperature. It is also used as structural ceramic as it is wear-resistant and can endure severe mechanical stresses in thermal and corrosive environments. It can be used for optical, di-electrical, biomedical and thermal applications (Ngo et al., 2018). A study by Gonzalez et al. focused on the production of 3D printed aluminium oxide through binder jetting. He observed that 3D product made from powder particles did well in mechanical testing and produced dense structures of $\mathrm{Al}_{2} \mathrm{O}_{3}$ with features to be used in electrical and biomedical applications (Gonzalez et al., 2016). Alumina 3D products are also fabricated from stearic acid coated aluminium and dextrin coated aluminium oxide followed by the reaction-bonding process via binder jetting. Appreciable density of $65 \%$ and flexural strength of 4-5 MPa was attained (Solis et al., 2019). Kunchala et al. study the influence of the addition of nanoparticles to the liquid binder, which has a positive impact on the printability and mechanical performance of 3D printed alumina powder (Kunchala and Kappagantula, 2018).

\subsubsection{Porcelaine}

Porcelain is another ceramic material that is widely 3D printed for dental applications like denture teeth, artificial teeth, porcelain crowns, bridgework (Ngo et al., 2018). Moreover, additives like magnesia $(\mathrm{MgO})$, zinc oxide $(\mathrm{ZnO})$, silica $(\mathrm{SiO} 2)$, Strontia $\mathrm{SrO})$ have been added to calcium phosphates to enhance biological and physical behaviour of scaffolds (Ngo et al., 2018). Glass ceramic composite was developed by Suwanprateeb et al. by mixing HAP with wollastonite with much appreciable mechanical properties (Suwanprateeb et al., 2009). Hafnium-free zirconium is also 3D printed, which found its applications in nuclear power sectors for tubing element as it has low thermal neutron absorption and low susceptibility to radiations (Ianko et al., 2018).

\subsubsection{Concrete}

Concrete is one of the most important ceramic products created. A similar technology to inject printing called contouring crafting is used for ceramic products which use large nozzles to extrude the concrete paste. The product has trowel like appearance, which is attached to printhead (Khoshnevis, 2004). The fresh properties of concrete are the most critical aspect for successful contour crafting. The 3D printing of complex concrete structures depends on the high workability 
of extrusion and strength of the concrete to support subsequent layers, i.e. buildability (Le et al., 2012). Minas et al. worked with the 3D printed ceramic foam ink into the hierarchal porous ceramic with a high strength to weight ratio (Minas et al., 2016). Gosselin et al. used on a process in which pumping of the accelerator and premix mortar combines in a separate tube at printhead before extrusion. This retains the early fresh strength of the concrete for the successful buildability. This process enabled the manufacturing of more massive structures with complex geometries without temporary supports (Gosselin et al., 2016). Le et al. (2012)developed high-performance 3D printed polypropylene fibre-reinforced mortal consisting of fly ash, silica fumes, sand and Portland cement with the addition of superplasticizers and retarder and showed enhanced workability for extrusion through a $9 \mathrm{~mm}$ diameters. Interlayer adhesion between concrete was also a challenge. Therefore, a study was conducted by Zareiyan and Khoshnevis investigated that smaller maximum aggregate size and higher cement to aggregate content yielded high interlayer strength due to better bonding (Zareiyan and Khoshnevis, 2017).

Powder-bed additive manufacturing needs to be further developed to create high strength concrete structures. Therefore, efforts are being made to initiate freedom of design and building complex structures with cheaper materials to produce 3D printed concrete (Ngo et al., 2018).

\subsection{Special Materials}

\subsubsection{Smart Materials}

The objects having an ability to change their shape and geometry under the influence of change in external conditions like heat, humidity, pressure, water is called smart materials. Smart materials produced by 3D printing are used in self-evolving structures and soft robotics. Shape memory alloys like nickel-titanium (Humbeeck, 2018) or shape memory polymers (Yang et al., 2016) are extensively developed by 3D printing. These are used in microelectromechanical devices or biomedical implants. 3D printing enables to replicate and formulate the complex shapes of shape memory materials and is evaluated based on dimensional accuracy, density and surface roughness (Shahrubudin et al., 2019).

Additionally, piezoelectric materials are also harvested via 3D printing. 3D printing will accelerate the production of smart materials for innovation and introducing to the common public (Dilberoglu et al., 2017). 3D printing is an excellent method to fabricate devices which are capable of integrating many distinct forms of materials. Lewis and Ahn (2015) explained various types of conducting polymers like quantum dot nanoparticles, conducting polymers, elastomeric matrix, metals leads, and UV adhesive transparent substrate layer and these materials can be fully integrated into devices with active applications and properties.

\subsubsection{Biomaterials}

Biopolymers, both natural and synthetic, are being 3D printed for use in regenerative medicine and organ transplantation. Chitosan, sodium alginate, and acrylates-based polymers are among the materials used (Lewis and Ahn, 2015). It is also feasible to create functional live tissues in 3D. Kang and colleagues developed an integrated tissue organ printing method capable of producing human-scale tissues with high mechanical strength (Liu et al., 2019). Soft active materials are now used in bio-applications because they exhibit substantial elastic deformation in response to environmental stimuli such as light, heat, and electricity. Wearable gadgets, artificial muscles, biomedical equipment, and other smart items are made with shape memory polymers, hydrogels, and dielectric elastomers (Ge et al., 2016). 
Organs on chips, or micro-physiological systems, are also being developed to replicate the structure and functioning of native tissues (Lewis and Ahn, 2015). 4D printing technique, which involves printing 3D structures that may actively shift configurations over time in response to external stimuli, was recently developed. When heated, hydrogels that swell as solvent molecules diffuse into the polymer network and shape memory polymers can be fixed to permanent shapes. Active valves made of thermally sensitive hydrogels, self-temporarily deformed shapes and recovering evolving structures actuated by multilayer joints, pattern transformations by heat-shrinkable polymers, and biomimicry by anisotropic hydrogel composites made of cellulose fibrils are all examples of 4D hydrogels in use (Ge et al., 2016).

\subsubsection{Hybrid Materials}

$3 \mathrm{D}$ printing of hybrids is an important direction in the printing field which combines different ink materials and printing techniques to achieve better properties of final printed objects (Fafenrot et al., 2017) e.g. polymeric scaffolds (Kim et al., 2008) as shown in Figure 7. The current AM technology cannot simultaneously work with metallic between each other (Wang and Liu, 2014). A study by Wang and Liu (2014) formulated a hybrid 3D printed product using a low melting alloy Bi35In48.6Sn16Zn0.4 with silicone rubber which will solidify in a room temperature after leaving for some time (Wang and Liu, 2014). Therefore, the clear identification of melting points of the input material is the key to determine whether 3D printing of the hybrid materials will work smoothly or not (Wang and Liu, 2014).

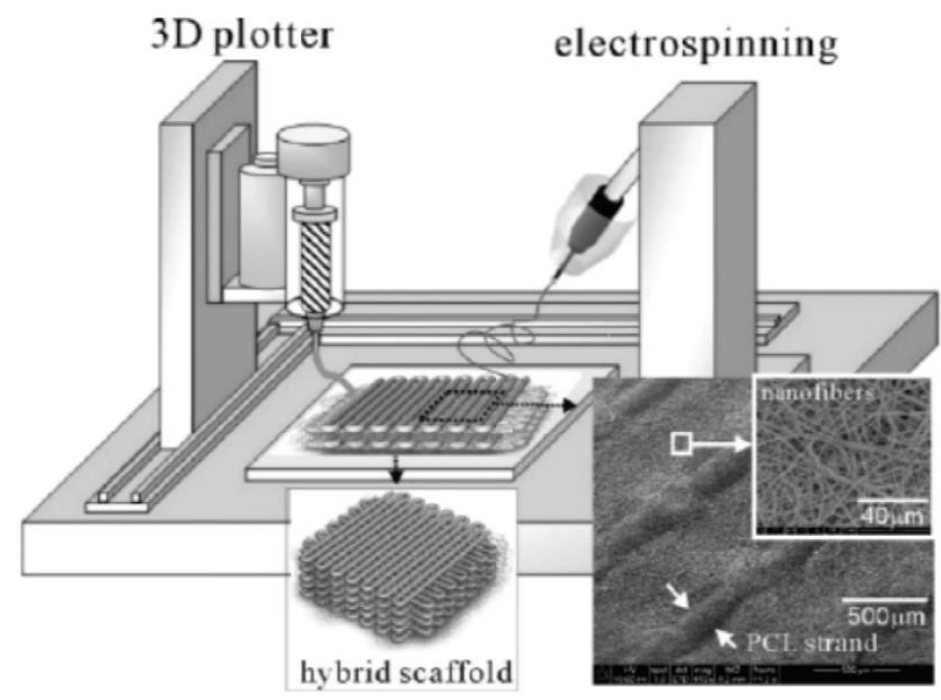

Figure 7. Schematic of 3D printing of hybrid process.

Soft lithography technique has been adopted to form a pattern of liquid-phase electronic circuit on an elastomer substrate using gallium-indium alloy (Tabatabai et al., 2013). Dual colour polymer light emitting pixels are made by utilizing hybrid inkjet printer with a combined pin-hole free polymer layer (Chang et al., 1998). it has also been used to fabricate viable cartilage tissues (Xu et al., 2013). A hybrid bionic ear was also made using cell seeded hydrogel matrix infused with silicone and silver nanoparticles (Mannoor et al., 2013). It must be ensured that metal ink is always 
in liquid state for 3D printing of hybrid materials (Wang and Liu, 2014). In order to achieve better toughness and high thermal stability, organic and inorganic components are mixed together in a perspective route to achieve hybrid products (Shukrun et al., 2018). Kotz et al reported a project of hybrid material consisting of inks with silica nanoparticles which are dispersed in organic photopolymerizable resins and results in a ceramic object (Kotz et al., 2017). The use of hybrid UV curable materials produced by photolithography have been reported (Zhang et al., 2013). The most common precursors used for hybrid materials formulation are organically modified silanes (Philipp and Schmidt, 1984). Other materials include epoxy based 3-glicydyloxypropyl-trimethoxysilane (GPTMS), acrylic based 3-methacryloxypropyltrimethoxysilane (MAPTMS), acryloxypropyltrimethoxysilane (APTMS), and methacrylphenyl polyhedral oligomeric silsesquioxanes (Philipp and Schmidt, 1984).

\subsubsection{Others}

$3 \mathrm{D}$ printing has the ability to create multilayered pieces made of lunar dust, which might be used to inhabit the moon (Humbeeck, 2018). 3D printing is also used to make food goods such as meat, chocolate, pizza, candy, and spaghetti (Feng et al., 2019). This procedure is considered healthy since it allows the consumer to customize the components without sacrificing nutrition or taste, and it is done by machine, eliminating human interaction (Wang and Liu, 2014). The jeweler and textile industries can benefit from AM technology because it allows for faster product replication, lower costs, and lower supply chain costs (Lewis and Ahn, 2015).

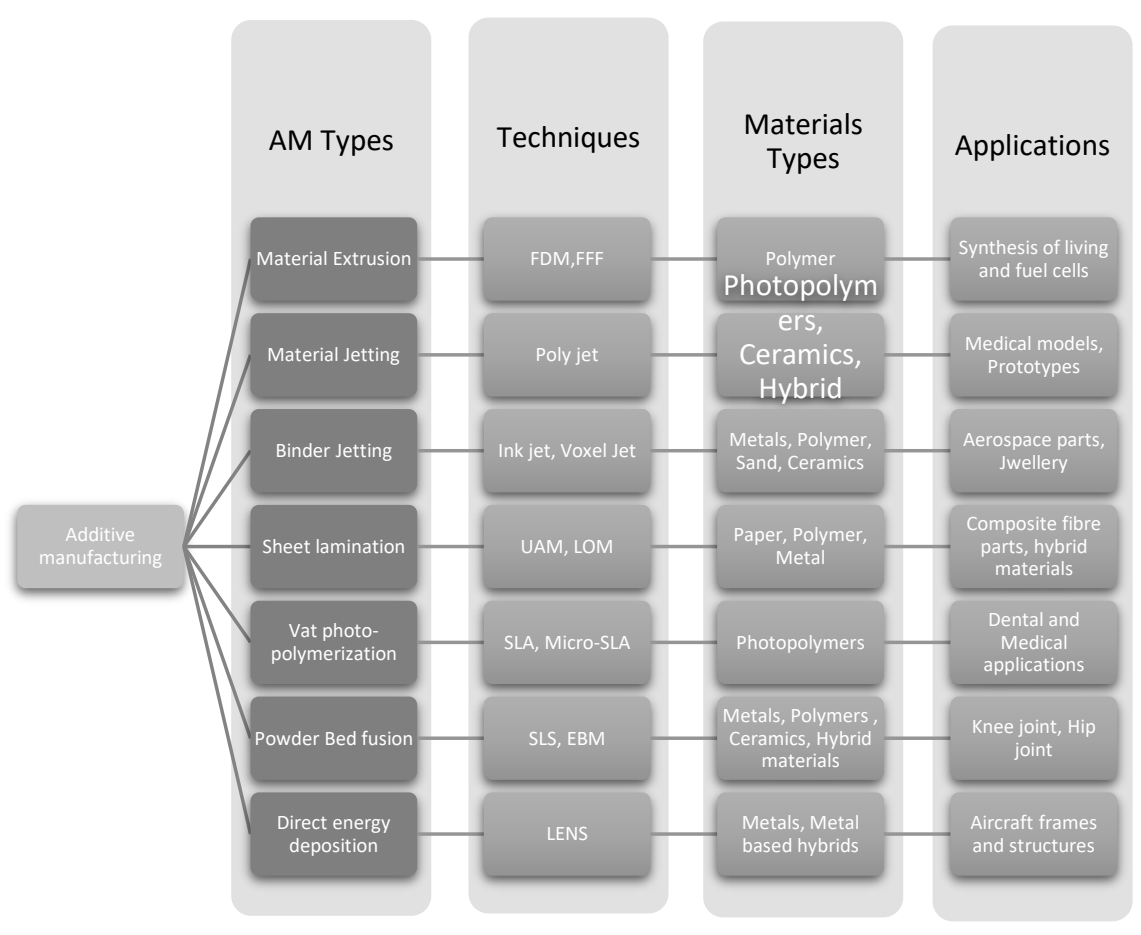

Figure 8. The additive manufacturing process and materials. 


\section{Conclusions and Future Prospects}

This review article precisely summarizes the types, applications and materials used in additive manufacturing technique. Additive manufacturing is versatile in terms of speed, resolution, cost, and energy and can be processed with a variety of materials, including metals, polymers, ceramics, and composites. There is a new trend of fabricating new materials via AM like smart materials, biomaterials, nanomaterials to achieve the required product outcome. In $3 \mathrm{D}$ printing, materials are fed in the form of paste, wire, powder, sheets, and inks. Polymers are still considered ubiquitous material for AM and the most common polymers used are ABS, PS, PLA, PC, polyamides, and photopolymer resins reinforced with fillers, fibres, and nanomaterials to yield composites to enhance mechanical properties. Metals are also used mainly in the form of powders or wires. Ceramics have an ability to tailor strength to weight ratio by tailoring design and material. Figure 8 summarize the study the additive manufacturing process and materials with some possible applications.

In the future, additive manufacturing will no longer be regarded a stand-alone process, but rather a vital component of a smart multi-process system. Interdisciplinary research activities are more likely to grow significantly. Furthermore, AM is intended to handle issues such as diminishing waste resources, energy reduction, and workload distribution. However, it still has drawbacks such as high costs, limited material input, poor mechanical performance, and regulatory concerns (Ngo et al., 2018). Furthermore, converting a CAD model to a 3D printed object frequently leads in faults and inaccuracies, particularly when dealing with curved parts and geometries (Ngo et al., 2018). In order to compete with traditional ways, AM technology, despite being a revolutionary approach for making things for specialized niches, need further improvement.

\footnotetext{
Abbreviations

$\mathrm{ABS}=$ acrylonitrile butadiene styrene

$\mathrm{AM}=$ Additive Manufacturing

$\mathrm{CNT}=$ Carbon Nanotubes

$\mathrm{DEP}=$ Direct Energy Deposition

$\mathrm{DLP}=$ Digital Light Processing

$\mathrm{EBM}=$ Electron Beam Machining

$\mathrm{EMI}=$ Electromagnetic Interference

$\mathrm{FFF}=$ Fused Filament Fabrication

FDM= Fused Deposition Modelling

HAP $=$ Hydroxyapatite

LOM= Laminated Object Manufacturing

$\mathrm{PBF}=$ Powder Bed Fusion

$\mathrm{PC}=$ Polycarbonate

$\mathrm{PCL}=$ polycaprolactone

$\mathrm{PE}=$ Polyethylene

PEEK=polyether ether ketone

PEGDA= polyethylene glycol diacrylate

$\mathrm{PEI}=$ polyethyleneimine

PEKK= Polyether ketone-ketone

PLA= Polylactic Acid

PMMA = Polymethylmethacrylate

$\mathrm{PP}=$ Polypropylene

$\mathrm{QD}=$ Quantum Dots

$\mathrm{RFI}=$ radio frequency interference

SLA $=$ Stereolithography
} 
SLS= Selective Laser Sintering

STL $=$ Surface Tessellation Language

$\mathrm{TCP}=$ Tricalcium phosphate

UAM= Ultrasound Additive Manufacturing

\section{Conflict of Interest}

The authors confirm that there is no conflict of interest to declare for this publication.

\section{Acknowledgments}

This research did not receive any specific grant from funding agencies in the public, commercial, or not-for-profit sectors. The authors would like to thank the editor and anonymous reviewers for their comments that help improve the quality of this work.

\section{References}

Arif, M.F., Alhashmi, H., Varadarajan, K.M., Koo, J.H., Hart, A.J., \& Kumar, S. (2020). Multifunctional performance of carbon nanotubes and graphene nanoplatelets reinforced PEEK composites enabled via FFF additive manufacturing. Composites Part B: Engineering, 184, 107625.

Asadi-Eydivand, M., Solati-Hashjin, M., Farzad, A., \& Osman, N.A.A. (2016). Effect of technical parameters on porous structure and strength of 3D printed calcium sulfate prototypes. Robotics and ComputerIntegrated Manufacturing, 37, 57-67.

Azam, F.I., Rani, A.M.A., Altaf, K., Rao, T.V.V.L.N., \& Zaharin, H.A. (2018). An in-depth review on direct additive manufacturing of metals. In 2018 IOP Conference Series: Materials Science and Engineering (Vol. 328, pp. 1-8). IOP Publishing. Batu Ferringhi, Penang. doi:10.1088/1757-899X/328/1/012005.

Berretta, S., Davies, R., Shyng, Y.T., Wang, Y., \& Ghita, O. (2017). Fused deposition modelling of high temperature polymers: exploring CNT PEEK composites. Polymer Testing, 63, 251-262.

Bhattacharya, M. (2016). Polymer nanocomposites-A comparison between carbon nanotubes, graphene, and clay as nanofillers. Materials, 9(4), 262.

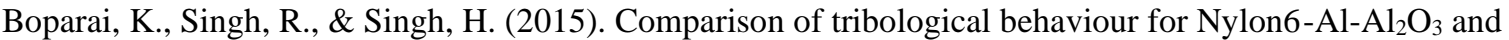
ABS parts fabricated by fused deposition modelling. Virtual and Physical Prototyping, 10(2), 59-66.

Boparai, K.S., Singh, R., Fabbrocino, F., \& Fraternali, F. (2016). Thermal characterization of recycled polymer for additive manufacturing applications. Composites Part B: Engineering, 106, 42-47.

Chang, S.C., Bharathan, J., Yang, Y., Helgeson, R., Wudl, F., Ramey, M.B., \& Reynolds, J.R. (1998). Dualcolor polymer light-emitting pixels processed by hybrid inkjet printing. Applied Physics Letters, 73(18), 2561-2563.

Chen, Z., Li, Z., Li, J., Liu, C., Lao, C., Fu, Y., \& He, Y. (2019). 3D printing of ceramics: A review. Journal of The European Ceramic Society, 39(4), 661-687.

Chung, H., \& Das, S. (2006). Processing and properties of glass bead particulate-filled functionally graded Nylon-11 composites produced by selective laser sintering. Materials Science and Engineering: A, 437(2), 226-234.

Council, N.R. (2004). Accelerating technology transition: bridging the valley of death for materials and processes in defense systems. The National Academies Press, Washington, DC.

Dehurtevent, M., Robberecht, L., Hornez, J.C., Thuault, A., Deveaux, E., \& Béhin, P. (2017). Stereolithography: A new method for processing dental ceramics by additive computer-aided manufacturing. Dental Materials, 33(5), 477-485. 
Demir, A.G., \& Previtali, B. (2017). Additive manufacturing of cardiovascular CoCr stents by selective laser melting. Materials \& Design, 119, 338-350.

Dilberoglu, U.M., Gharehpapagh, B., Yaman, U., \& Dolen, M. (2017). The role of additive manufacturing in the era of industry 4.0. Procedia Manufacturing, 11, 545-554.

Dinaharan, I., Nelson, R., Vijay, S.J., \& Akinlabi, E.T. (2016). Microstructure and wear characterization of aluminum matrix composites reinforced with industrial waste fly ash particulates synthesized by friction stir processing. Materials Characterization, 118, 149-158.

Dizon, J.R.C., Espera Jr, A.H., Chen, Q., \& Advincula, R.C. (2017). Mechanical characterization of 3Dprinted polymers. Additive Manufacturing, 20, 44-67.

Do, A.V., Khorsand, B., Geary, S.M., \& Salem, A.K. (2015). 3D printing of scaffolds for tissue regeneration applications. Advanced Healthcare Materials, 4(12), 1742-1762.

Eckel, Z.C., Zhou, C., Martin, J.H., Jacobsen, A.J., Carter, W.B., \& Schaedler, T.A. (2016). Additive manufacturing of polymer-derived ceramics. Science, 351(6268), 58-62.

Elliott, A.M., Ivanova, O., Williams, C., \& Campbell, T. (2012). An investigation of the effects of quantum dot nanoparticles on photopolymer resin for use in polyjet direct 3D printing. In 2012 23rd Annual International Solid Freeform Fabrication Symposium: An Additive Manufacturing Conference (pp. 988998). University of Texas at Austin. US.

Fafenrot, S., Grimmelsmann, N., Wortmann, M., \& Ehrmann, A. (2017). Three-dimensional (3D) printing of polymer-metal hybrid materials by fused deposition modeling. Materials, 10(10), 1199.

Feng, C., Zhang, M., \& Bhandari, B. (2019). Materials properties of printable edible inks and printing parameters optimization during 3D printing: A review. Critical Reviews in Food Science and Nutrition, 59(19), 3074-3081.

Ferreira, R.T.L., Amatte, I.C., Dutra, T.A., \& Bürger, D. (2017). Experimental characterization and micrography of 3D printed PLA and PLA reinforced with short carbon fibers. Composites Part B: Engineering, 124, 88-100.

Ge, Q., Sakhaei, A.H., Lee, H., Dunn, C.K., Fang, N.X., \& Dunn, M.L. (2016). Multimaterial 4D printing with tailorable shape memory polymers. Scientific Reports, 6(1), 1-11.

Gonzalez, J.A., Mireles, J., Lin, Y., \& Wicker, R.B. (2016). Characterization of ceramic components fabricated using binder jetting additive manufacturing technology. Ceramics International, 42(9), 10559-10564. doi:10.1016/j.ceramint.2016.03.079.

Gosselin, C., Duballet, R., Roux, P., Gaudillière, N., Dirrenberger, J., \& Morel, P. (2016). Large-scale 3D printing of ultra-high performance concrete - a new processing route for architects and builders. Materials \& Design, 100, 102-109. doi:10.1016/j.matdes.2016.03.097.

Han, Q., Geng, Y., Setchi, R., Lacan, F., Gu, D., \& Evans, S.L. (2017). Macro and nanoscale wear behaviour of $\mathrm{Al}-\mathrm{Al}_{2} \mathrm{O}_{3}$ nanocomposites fabricated by selective laser melting. Composites Part B: Engineering, 127, 26-35. doi:10.1016/j.compositesb.2017.06.026.

Han, Y., Wang, F., Wang, H., Jiao, X., \& Chen, D. (2018). High-strength boehmite-acrylate composites for 3D printing: Reinforced filler-matrix interactions. Composites Science and Technology, 154, 104-109.

Hofmann, D.C., Kolodziejska, J., Roberts, S., Otis, R., Dillon, R.P., Suh, J.O., Liu, Z.K., \& Borgonia, J.P. (2014a). Compositionally graded metals: a new frontier of additive manufacturing. Journal of Materials Research, 29(17), 1899-1910. doi:10.1557/jmr.2014.208.

Hofmann, D.C., Roberts, S., Otis, R., Kolodziejska, J., Dillon, R.P., Suh, J.O., Shapiro, A.A., Liu, Z.K., \& Borgonia, J.P. (2014b). Developing gradient metal alloys through radial deposition additive manufacturing. Scientific Reports, 4(1), 1-8. 
Humbeeck, J.V. (2018). Additive manufacturing of shape memory alloys. Shape Memory and Superelasticity, 4(2), 309-312.

Ianko, T., Panov, S., Sushchyns'ky, O., Pylypenko, M., \& Dmytrenko, O. (2018). Zirconium alloy powders for manufacture of 3D printed articles used in nuclear power industry. Atomic Science and Technology, 1, 148-153.

Isaac D., Nelson R., Vijay S.J., Akinlabi E.T. (2016). Microstructure and wear characterization of aluminium matrix composites reinforced with industrial waste fly ash particulates synthesized by friction stir processing. Materials Characterization, 118, 149-158.

Khoshnevis, B. (2004). Automated construction by contour crafting-related robotics and information technologies. Automation in Construction, 13(1), 5-19. doi:10.1016/j.autcon.2003.08.012.

Kim, G., Son, J., Park, S., \& Kim, W. (2008). Hybrid process for fabricating 3D hierarchical scaffolds combining rapid prototyping and electrospinning. Macromolecular Rapid Communications, 29(19), 1577-1581.

Kishore V., Chen X., Ajinjeru C., Hassen A., Lindahl J., Failla J., Kunc V., \& Duty C. (2016). Additive manufacturing of high performance semicrystalline thermoplastics and their composites. In 2016 Solid Freeform Fabrication Symposium Conference. Austin, Texas, United States of America, 906-915.

Körner, C., Helmer, H., Bauereiß, A., \& Singer, R.F. (2014). Tailoring the grain structure of IN718 during selective electron beam melting. In 2014 MATEC Web of Conferences (Vol. 14, pp. 1-6). EDP Science. France.

Kotz, F., Arnold, K., Bauer, W., Schild, D., Keller, N., Sachsenheimer, K., Nargang, T.M., Richter, C., Helmer, D., \& Rapp, B.E. (2017). Three-dimensional printing of transparent fused silica glass. Nature, 544(7650), 337-339.

Kuang, X., Wu, J., Chen, K., Zhao, Z., Ding, Z., Hu, F., Fang, D., \& Qi, H.J. (2019). Grayscale digital light processing 3D printing for highly functionally graded materials. Science Advances, 5(5), 1-9.

Kunchala, P., \& Kappagantula, K. (2018). 3D printing high density ceramics using binder jetting with nanoparticle densifiers. Materials \& Design, 155, 443-450.

Kuo, C.C., Liu, L.C., Teng, W.F., Chang, H.Y., Chien, F.M., Liao, S.J., Kuo, W.F., \& Chen, C.M. (2016). Preparation of starch/acrylonitrile-butadiene-styrene copolymers (ABS) biomass alloys and their feasible evaluation for 3D printing applications. Composites Part B: Engineering, 86, 36-39.

Le, T.T., Austin, S.A., Lim, S., Buswell, R.A., Gibb, A.G.F., \& Thorpe, T. (2012). Mix design and fresh properties for high-performance printing concrete. Materials and Structures, 45(8), 1221-1232.

Lee, J.Y., An, J., \& Chua, C.K. (2017). Fundamentals and applications of 3D printing for novel materials. Applied Materials Today, 7, 120-133. doi:10.1016/j.apmt.2017.02.004.

Lewis, J.A., \& Ahn, B.Y. (2015). Three-dimensional printed electronics. Nature, 518(7537), $42-43$.

Ligon, S.C., Liska, R., Stampfl, J., Gurr, M., \& Mülhaupt, R. (2017). Polymers for 3D printing and customized additive manufacturing. Chemical Reviews, 117(15), 10212-10290.

Liu, F.H., Shen, Y.K, \& Liao, Y.S. (2011). Selective laser gelation of ceramic matrix composites. Composites Part B: Engineering, 42(1), 57-61.

Liu, L., Meng, Y., Dai, X., Chen, K., \& Zhu, Y. (2019). 3D printing complex egg white protein objects: properties and optimization. Food and Bioprocess Technology, 12(2), 267-279.

Love, L.J., Kunc, V., Rios, O., Duty, C.E., Elliott, A.M., Post, B.K., Smith, R.J., \& Blue, C.A. (2014). The importance of carbon fiber to polymer additive manufacturing. Journal of Materials Research, 29(17), 1893-1898. 
Manapat, J.Z., Chen, Q., Ye, P., \& Advincula, R.C. (2017). 3D printing of polymer nanocomposites via stereolithography. Macromolecular Materials and Engineering, 302(9), 1-13. doi:10.1002/mame.201600553.

Mannoor, M.S., Jiang, Z., James, T., Kong, Y.L., Malatesta, K.A., Soboyejo, W.O., Verma, N., Gracias, D.H., \& McAlpine, M.C. (2013). 3D printed bionic ears. Nano Letters, 13(6), 2634-2639.

Martin, J.H., Yahata, B.D., Hundley, J.M., Mayer, J.A., Schaedler, T.A., \& Pollock, T.M. (2017). 3D printing of high-strength aluminium alloys. Nature, 549(7672), 365-369.

Maurath, J., \& Willenbacher, N. (2017). 3D printing of open-porous cellular ceramics with high specific strength. Journal of The European Ceramic Society, 37(15), 4833-4842.

Mertens, A., Delahaye, J., Dedry, O., Vertruyen, B., Tchuindjang, J.T., \& Habraken, A.M. (2020). Microstructure and properties of slm alsi10mg: understanding the influence of the local thermal history. Procedia Manufacturing, 47, 1089-1095.

Minas, C., Carnelli, D., Tervoort, E., \& Studart, A.R. (2016). 3D printing of emulsions and foams into hierarchical porous ceramics. Advanced Materials, 28(45), 9993-9999.

Mohiuddin, M., \& Hoa, S.V. (2011). Temperature dependent electrical conductivity of CNT-PEEK composites. Composites Science and Technology, 72(1), 21-27. doi:10.1016/j.compscitech.2011.08.018.

Mohiuddin, M., \& Van Hoa, S. (2011). Electrical resistance of CNT-PEEK composites under compression at different temperatures. Nanoscale Research Letters, 6(1), 1-5.

Mostafaei, A., Elliott, A.M., Barnes, J.E., Li, F., Tan, W., Cramer, C.L., Nandwana, P., \& Chmielus, M. (2021). Binder jet 3D printing-process parameters, materials, properties, modeling, and challenges. Progress in Materials Science, 119, 100707. doi:https://doi.org/10.1016/j.pmatsci.2020.100707.

Murr, L.E., Martinez, E., Hernandez, J., Collins, S., Amato, K.N., Gaytan, S.M., \& Shindo, P.W. (2012). Microstructures and properties of 17-4 PH stainless steel fabricated by selective laser melting. Journal of Materials Research and Technology, 1(3), 167-177. doi:10.1016/S2238-7854(12)70029-7.

Ngo, T.D., Kashani, A., Imbalzano, G., Nguyen, K.T. \& Hui, D. (2018). Additive manufacturing (3D printing): A review of materials, methods, applications and challenges. Composites Part B: Engineering, 143, 172-196. doi: doi:10.1016/j.compositesb.2018.02.012.

Nguyen, Q.T., Ngo, T., Tran, P., Mendis, P., Zobec, M., \& Aye, L. (2016). Fire performance of prefabricated modular units using organoclay/glass fibre reinforced polymer composite. Construction and Building Materials, 129, 204-215.

Nikzad, M., Masood, S.H., \& Sbarski, I. (2011). Thermo-mechanical properties of a highly filled polymeric composites for fused deposition modeling. Materials \& Design, 32(6), 3448-3456.

Panda, B., Unluer, C., \& Tan, M.J. (2019). Extrusion and rheology characterization of geopolymer nanocomposites used in 3D printing. Composites Part B: Engineering, 176, 107290.

Paolini, A., Kollmannsberger, S., \& Rank, E. (2019). Additive manufacturing in construction: A review on processes, applications, and digital planning methods. Additive Manufacturing, 30, 100894.

Philipp, G., \& Schmidt, H. (1984). New materials for contact lenses prepared from Si- and Ti-alkoxides by the sol-gel process. Journal of Non-Crystalline Solids, 63(1-2), 283-292.

Postiglione, G., Natale, G., Griffini, G., Levi, M., \& Turri, S. (2015). Conductive 3D microstructures by direct 3D printing of polymer/carbon nanotube nanocomposites via liquid deposition modeling. Composites Part A: Applied Science and Manufacturing, 76, 110-114.

Sanjairaj, V., Fuh, J.Y.H., \& Lu, W.F. (2017). 3D printing and 3D bioprinting in pediatrics. Bioengineering, 4(3), 1-11. doi:10.3390/bioengineering4030063. 
Santos, C.F.L., Silva, A.P., Lopes, L., Pires, I., \& Correia, I.J. (2012). Design and production of sintered $\beta$ tricalcium phosphate 3D scaffolds for bone tissue regeneration. Materials Science and Engineering: $C$, 32(5), 1293-1298. doi:https://doi.org/10.1016/j.msec.2012.04.010.

Seitz, H., Rieder, W., Irsen, S., Leukers, B., \& Tille, C. (2005). Three-dimensional printing of porous ceramic scaffolds for bone tissue engineering. Journal of Biomedical Materials Research. Part B Applied Biomaterials, 74(2), 782-788. doi:10.1002/jbm.b.30291.

Shahrubudin, N., Lee, T.C., \& Ramlan, R. (2019). An overview on 3D printing technology: technological, materials, and applications. Procedia Manufacturing, 35, 1286-1296.

Shemelya, C.M., Rivera, A., Perez, A.T., Rocha, C., Liang, M., Yu, X., Kief, C., Alexander, D., Stegeman, J., Xin, H., Wicker, R.B., MacDonald, E., \& Roberson, D.A. (2015). Mechanical, electromagnetic, and X-ray shielding characterization of a 3D printable tungsten-polycarbonate polymer matrix composite for space-based applications. Journal of Electronic Materials, 44(8), 2598-2607.

Shukrun, E., Cooperstein, I., \& Magdassi, S. (2018). 3D-printed organic-ceramic complex hybrid structures with high silica content. Advanced Science, 5(8), 1-7. doi:https://doi.org/10.1002/advs.201800061.

Sing, S.L., Tey, C.F., Tan, J.H.K., Huang, S., \& Yeong, W.Y. (2020). 2 - 3D printing of metals in rapid prototyping of biomaterials: Techniques in additive manufacturing. In: Narayan, R. (ed) Rapid Prototyping of Biomaterials (Second Edition). Woodhead Publishing, (pp. 17-40).

Singh, R., Singh, S., \& Fraternali, F. (2016). Development of in-house composite wire based feed stock filaments of fused deposition modelling for wear-resistant materials and structures. Composites Part B: Engineering, 98, 244-249.

Singh, S., Ramakrishna, S., \& Berto, F. (2020). 3D printing of polymer composites: a short review. Material Design \& Processing Communications, 2(2), 1-13. doi:https://doi.org/10.1002/mdp2.97.

Solis, D.M., Silva, A.V., Volpato, N., \& Berti, L.F. (2019). Reaction-bonding of aluminum oxide processed by binder jetting. Journal of Manufacturing Processes, 41, 267-272.

Song, Y., Li, Y., Song, W., Yee, K., Lee, K.Y., \& Tagarielli, V.L. (2017). Measurements of the mechanical response of unidirectional 3D-printed PLA. Materials \& Design, 123, 154-164.

Stansbury, J.W., \& Idacavage, M.J. (2016). 3D printing with polymers: challenges among expanding options and opportunities. Dental Materials, 32(1), 54-64.

Suwanprateeb, J., Sanngam, R., Suvannapruk, W., \& Panyathanmaporn, T. (2009). Mechanical and in vitro performance of apatite-wollastonite glass ceramic reinforced hydroxyapatite composite fabricated by 3D-printing. Journal of Materials Science: Materials in Medicine, 20(6), 1281-1289.

Tabatabai, A., Fassler, A., Usiak, C., \& Majidi, C. (2013). Liquid-phase gallium-indium alloy electronics with microcontact printing. Langmuir, 29(20), 6194-6200.

Tekinalp, H.L., Kunc, V., Velez-Garcia, G.M., Duty, C.E., Love, L.J., Naskar, A.K., Blue, C.A., Ozcan, S. (2014). Highly oriented carbon fiber-polymer composites via additive manufacturing. Composites Science and Technology, 105, 144-150.

Valentan, B., Kadivnik, Brajlih, T., Anderson, A., \& Drstvenaek, I. (2013). Processing poly (ether etherketone) an a 3D printer for thermoplastic modelling. Materiali in Tehnologije, 47(6), 715-721.

Vilaro, T., Colin, C., \& Bartout, J.D. (2011). As-fabricated and heat-treated microstructures of the TI-6AL4V alloy processed by selective laser melting. Metallurgical and Materials Transactions A, 42(10), 3190-3199.

Vora, P., Mumtaz, K., Todd, I., \& Hopkinson, N. (2015). AlSi12 in-situ alloy formation and residual stress reduction using anchorless selective laser melting. Additive Manufacturing, 7, 12-19. 
Vorndran, E., Klarner, M., Klammert, U., Grover, L.M., Patel, S., Barralet, J.E., \& Gbureck, U. (2008). 3D powder printing of $\beta$-tricalcium phosphate ceramics using different strategies. Advanced Engineering Materials, 10(12), 67-71.

Wang, L., \& Liu, J. (2014). Compatible hybrid 3D printing of metal and nonmetal inks for direct manufacture of end functional devices. Science China Technological Sciences, 57(11), 2089-2095.

Wang, X., Jiang, M., Zhou, Z., Gou, J., \& Hui, D. (2017). 3D printing of polymer matrix composites: A review and prospective. Composites Part B: Engineering, 110, 442-458.

Wiberg, A., Persson, J., \& Ölvander, J. (2019). Design for additive manufacturing - a review of available design methods and software. Rapid Prototyping Journal, 25(6), 1080-1094.

Wong, K.V., \& Hernandez, A. (2012). A review of additive manufacturing. International Scholarly Research Notices, 2012, 1-10.

Wycisk, E., Solbach, A., Siddique, S., Herzog, D., Walther, F., \& Emmelmann, C. (2014). Effects of defects in laser additive manufactured TI-6AL-4V on fatigue properties. Physics Procedia, 56, 371-378.

Xu, T., Binder, K.W., Albanna, M.Z., Dice, D., Zhao, W., Yoo, J.J., \& Atala, A. (2013). Hybrid printing of mechanically and biologically improved constructs for cartilage tissue engineering applications. Biofabrication, 5(1), 1-10.

Yakout, M., Elbestawi, M.A., \& Veldhuis, S.C. (2018). A review of metal additive manufacturing technologies. Solid State Phenomena, 278, 1-14.

Yang, Y., Chen, Y., Wei, Y., \& Li, Y. (2016). 3D printing of shape memory polymer for functional part fabrication. The International Journal of Advanced Manufacturing Technology, 84(9), 2079-2095.

Zareiyan, B., \& Khoshnevis, B. (2017). Effects of interlocking on interlayer adhesion and strength of structures in 3D printing of concrete. Automation in Construction, 83, 212-221.

Zhang, H., Zhu, H., Qi, T., Hu, Z., \& Zeng, X. (2016). Selective laser melting of high strength Al-Cu-Mg alloys: Processing, microstructure and mechanical properties. Materials Science and Engineering: A, $656,47-54$.

Zhang, X., Que, W., Chen, J., Hu, J., Gao, T., \& Liu, W. (2013). Sol-gel concave micro-lens arrays fabricated by combining the replicated PDMS soft mold with UV-cured imprint process. Applied Physics B, 113(2), 299-306.

Zocca, A., Colombo, P., Gomes, C.M., \& Günster, J. (2015). Additive manufacturing of ceramics: issues, potentialities, and opportunities. Journal of the American Ceramic Society, 98(7), 1983-2001. 